International Journal of Linguistics, Literature and Translation (IJLLT)

ISSN: 2617-0299 (Online); ISSN: 2708-0099 (Print)

DOI: $10.32996 / \mathrm{jjllt}$

Journal Homepage: www.al-kindipublisher.com/index.php/ijllt

\title{
Evaluation Methods in Teaching Translation by Saudi University Instructors under Coronavirus Pandemic
}

Eman Mohammad Mahmoud AlOneen

Lecturer at University of Hafr AlBatin, Saudi Arabia

Corresponding Author: Eman Mohammad Mahmoud AlOneen, E-mail: eman-jor@hotmail.com

ARTICLE INFORMATION ABSTRACT

Received: November 08, 2020

Accepted: December 02, 2020

Volume: 3

Issue: 12

DOI: $10.32996 /$ ijllt.2020.3.12.5

\section{KEYWORDS}

Evaluation methods; teaching

translation; Coronavirus

pandemic; Saudi university

instructors
Coronavirus pandemic has posed challenges in evaluating students' performance in educational institutions all over the world. Therefore, university instructors may encounter some problems in evaluating their students fairly through online teaching since it was not an easy task before this worldly crisis. The current study aims at investigating the perspectives of instructors who teach translation courses at some Saudi universities towards the followed evaluation methods in teaching translation courses during Coronavirus pandemic. Two methods were used to collect data: simple observation and online questionnaire. The participants were 21 instructors from 10 Saudi universities. The findings of this study show that using machine translation and CAT tools by students in doing assessment tasks does not guarantee fairness among students during Coronavirus pandemic regardless of the nature of translation courses. In addition, online exams and assignments are less fair to show the individual differences among students compared with written exams before Coronavirus pandemic. To evaluate students' performance in translation courses fairly, the participants of this study suggested some solutions such as modifying questions' patterns of some translation exams and assignments to cope with online teaching, emphasizing the importance of live sessions and online participation as assessment tasks for students during Coronavirus pandemic, using other evaluation methods such as live oral assessment, editing texts, multiple choice editing questions, etc. The study concludes with some recommendations for future research.

\section{Introduction}

Evaluating students is a crucial part within the teaching process. It checks what students have learned and it leads instructors to improve the learning process. However, Coronavirus pandemic has affected the entire teaching process at universities all over the world. Although some universities have already adopted online teaching before Coronavirus pandemic with face to face teaching such as Harvard, Oxford, Cambridge, etc.(Demuyakor, 2020, p.2), other universities are moving now to online teaching which may impose some challenges regards the process of evaluating students fairly and satisfactorily.

Some universities modified some evaluation methods based on the overall change of teaching mechanism, i.e from traditional teaching to online teaching or blended teaching. As a result, this required more efforts from university instructors to cope with online teaching under Coronavirus pandemic. For example, online exams were used instead of final written exams in translation courses and other courses during the second term of the university year 2019-2020 at some Saudi public universities. Others used oral exams and online assignments instead of paper assignments. To highlight other possible challenges regarding student evaluation during Coronavirus pandemic, the researcher attempts to answer the following questions through this study:

1. What are the difficulties encountered university instructors who teach translation courses in evaluating their students?

2. How do instructors evaluate their students' translations during Coronavirus crisis?

K C AL-KINDI CENTER

$\mathbf{R}$ D FOR RESEARCHA

Your gateway to world-closs research
Published by Al-KindiCenter for Research and Development. Copyright (c) the author(s). This is an open access article under CC BY license (https://creativecommons.org/licenses/by/4.0/) 
3. Are there suggested evaluation methods for teaching translation courses by instructors at Saudi universities to cope with the current crisis?

The present study shows the perspectives of 21 translation instructors working at 10 big Saudi universities regards translation evaluation methods in the context of university translation classes. These instructors were selected randomly to gain an understanding of the evaluation methods they used in translation classes under Coronavirus crisis. Two methods were used to analyzed the perspectives of instructors: the online questionnaire and simple observation.

\section{Literature Review}

Translation evaluation is one of the important issues in the field of translation studies in particular applied translation studies. This branch covers three areas namely translation training, translation aids and translation criticism where translation evaluation has been discussed according to Holmes' framework (Munday, 2012). Some researchers_discussed the issue of translation evaluation within the context of teaching translation for university students but from different corners.

One of these studies defined translation evaluation within the process of teaching translation as a way to analyze, discuss and improve students' translation drafts on the bases of ST-TT comparative analysis where other linguistic and paralinguistic aspects of texts will be taken into consideration (AIMelhi,2014). It emphasized the importance of realizing the sources of text difficulty in evaluating the quality of translation. These sources were categorized into two groups: translation factors (for example, textual aspects) and translator factors as translation competence, training of the translators among others. Then AlMelhi (2014) described how to measure translation difficulty and assess the quality of translation. Finally, he proposed a suggested translation evaluation model and illustrated the features of this suggested model that can be used by Arab students of translation studies This covers three phases namely evaluation of bilingual competence, evaluation of interlingual competence, evaluation of intercultural transfer competence. Within this model, a useful rubric was suggested to be used by translation instructors in evaluating their students' translations. However, the previous suggested model may seem general and not applicable for all translation courses and text types. Other researchers like Wu (2013) discussed translation evaluation / assessment with relation to one type of translation especially interpreting while other developed empirical studies such as the research of Al-Qinai (2000) who was interested in evaluating the translation of certain types of texts as advertising on the base of assessment approaches like House pragmatic -textual approach, etc. Others researchers like Conde (2013) were interested in analyzing and comparing types of errors in given translations of a set of certain original texts and illustrated how evaluators from certain environments such as professional translators, translation teachers, potential addresses of the texts and translation students judge the quality of given translations. He mentioned that there are two types of errors namely language errors and translation errors in translated texts. The former errors are related to TT expressions, vocabularies, syntactic and grammatical forms, etc. while the latter errors are "explained by the existence of a previous text, the source text upon which the target text depends."p. 99. The results showed that language errors are much more common in translation evaluation; however, translation errors contribute more on the variability of the marks issued. Regarding the quality judgments, Conde (2013, p.97) added "Moreover, language errors play a key role on teachers' evaluations, whereas translation errors are more decisive among students." Although the previous study is significant, it was noticed that the number of translation teachers was low only (10) teachers and their practical experiences were not displayed in Conde' research and this may affect the overall findings. Some researchers investigated the issue of objectivism in translation evaluation and discussed translation strategies in evaluating students' translations from the traditional strategies which focus on linguistic aspects of both languages ST/ TT to the modern ones which focus on paralinguistic aspects (Mobarki \& Aminzadeh, 2012). They concluded that both strategies are being used to evaluate translation competence of translation students. Models of translation evaluation namely holistic and error analysis was the interest area for some researchers. Therefore, it is crucial to define these two main models in this study:

1. Holistic model: According to Dewis (2015), this model, "holistic assessment", "focuses on overall characteristics of the object being assessed such as (in the case of translated texts) reader impression, sentiment, clarity, accuracy, style, whether it enables a task to be completed, and so forth" p. 37

2. Error analysis model: According to Conde, $(2013$, p.98) this model "analytical assessment model" focuses on the number of errors that are first identified, then quantified and then subtracted from the totality. Other researcher used the term "Summative assessment" to indicate the same above evaluation method i.e. error analysis model since it evaluates a translation product according to the errors committed by translators (Dewis, 2015). Preferring one model over another model during the evaluation process was an important issue which has been argued by researchers and translation instructors. For example, the importance of using error analysis in evaluating students' translation was emphasized by Kiraly 
(1995) in helping translation teachers to understand student problems in translation whether it is linguistic, cultural, textual and other problems. On the other hand, some of the interesting results of a recent study revealed that error analysis method could lead to unreasonable failure rate among MA students at the postgraduate translation final project at the faculty of languages and translation at King Khalid University in KSA (Bahameed, 2019). One of the results of the previous study is that the holistic method could not show the individual differences among MA students. Thus, the hypothesis of Bahameed's study regards the appropriateness of using the holistic method in evaluating MA students has not been confirmed and this means there is a necessity to conduct more studies on this research area in particular. In addition, the number of particpants in his study was low (only 5 MA students) and it focused on the final product more than the translating process in oder to develop evaluation methods in teaching translation courses by translation instructors. Another empirical study on the effectiveness of two translation evaluation models was mentioned in Dewis 's dissertation (Dewis, 2015) which compared two translation assessment models namely the Indonesian translation bandscale (LBI Bandscale) which is a scale assessment model used in the Translation Center of the International Language Institution of the University of Indonesia, and the second model is the American Translators Association Framework for Error Marking (ATA framework) which is an error analysis model. He attempted to reveal which one of these two models is more effective in general translation classes held at Translation Center of the International Language Institution of the University of Indonesia and to show the perspectives of students in translation regarding the preferred model for improving their translations. He summarized that "the ATA Framework appears to be more effective than the LBI Brandscale." "However, from all the t-test results, there is no significant difference between the two assessment models." p.134. The participants of the online survey in this study also emphasized that both of these models are effective and these models help them in improving their translations. The current study is different compared with the Dewis's dissertation in related to the participants i.e. she focused on the perspectives of translation students while this study mainly focuses on the perspectives of translation instructors.

\section{Methodology}

This study was a descriptive study in which translation instructors' methods about the assessment of students' translations in universities were investigated during the Coronavirus era.

\subsection{Participants}

The participants were instructors who taught translation courses in different Saudi universities. 21 translation instructors participated in this research and completed the online questionnaire. The participants were selected randomly from 10 Saudi universities which teach translation courses 6 instructors from King Saud University, 4 instructors from A-Imam Mohammad Ibn Saud Islamic University, 2 instructors from King Khaled University, 2 instructors from Qassim University, 2 instructors from Saudi Electronic University, 1 instructor from Princess Nourah Bint Abdulrahman University, 1 instructor from Tabouk University, 1 instructor from Taibah University, 1 instructor from Najran University and 1 instructor from Jouf University). The participants have various academic positions at Saudi universities as following (1 professor, 5 associate professors, 13 assistant professors and 2 lecturers). Some Saudi universities have independent departments of translation whereas other Saudi universities have only departments of English where some translation courses are given by experienced instructors in teaching translation. Because of the low number of participants from departments of translation, other participants were selected randomly from departments of English. Table (1) and Table (2) show the teaching experience and majors of 21 participants in this research.

Table (1) Teaching experience of participants

\begin{tabular}{|l|l|}
\hline Years of experience & Number of instructors \\
\hline $1-3$ & 7 \\
\hline $4-6$ & 8 \\
\hline $7-10$ & 3 \\
\hline More than 10 years & 3 \\
\hline
\end{tabular}

Table (2) Majors of participants

\begin{tabular}{|l|l|}
\hline Number of instructors & Major \\
\hline 10 & Translation \\
\hline 7 & Applied Linguistics \\
\hline 2 & Linguistics \\
\hline 1 & Computational Linguistics \\
\hline 1 & TESOL \\
\hline
\end{tabular}




\subsection{Instruments}

The main purpose of this study is to provide university instructors with some suggested evaluation methods for translation courses to cope with online teaching during Coronavirus crisis. The researcher used two main methods to collect data: simple observation of the researcher and online questionnaire.

\subsubsection{Simple Observation}

Generally speaking, university instructors have to follow a course plan and a course specification in teaching all the courses. This step provides university instructors with required information among them, teaching strategies and evaluation methods for example, exams, assignments, class activities, participation and other methods. In this research, the specifications of two courses (Translating Text Types and Creative Translation) were taught in the first term of the academic year 2019-2020 at the University College at AlKhafji , University of Hafr AlBatin, KSA.The objective of this comparison between these two courses is to show the common evaluation methods in evaluating students before Coronavirus pandemic and link the evaluation methods in these specifications with some related studies in literature review. Table 3 shows the evaluation/assessment methods used by instructors in these two courses according to the course specifications:

\section{Table (3) Assessment tasks in two university translation courses}

\begin{tabular}{|l|l|}
\hline $\begin{array}{l}\text { Assessment tasks for students (Course Title: } \\
\text { Translating Text Types) }\end{array}$ & Assessment tasks for students \\
& (Course Title: Creative Translation) \\
\hline Quiz 1 & Quiz1 \\
\hline Mid-Term & Mid-Term \\
\hline Class activities & Assignment \\
\hline Assignment & Class activities \\
\hline Final exam & Final exam \\
\hline Attendance \& participation & Attendance \& participation \\
\hline
\end{tabular}

By comparing the course specifications by the researcher, it was noticed that listing assessments tasks for students in course specifications is not sufficient for instructors to describe evaluation/ assessment strategies especially for new translation instructors whose practical experiences may be modest. In addition, translation instructors may need to know general criteria for evaluating their students' translations in each practical course and main models of translation evaluation were not mentioned there to check if they are effective or no by experienced instructors. Such additions help instructors in evaluating students and enrich course specifications with important guides taken from related studies. During Coronavirus pandemic evaluating students' performance might seem more difficult than before due to various factors affect the entire learning process. Thus, the researcher conducted an online questionnaire to measure the perceptions of Saudi university instructors about evaluating translation courses before and during this critical era.

\subsubsection{Questionnaire}

To achieve the objectives of the present study, the researcher designed an online questionnaire by google forms on the basis of reviewing several translation studies related to evaluation translation. The questionnaire contained four parts. The first part devoted to basic data of instructors including age, university name, academic position, major, years of experience, etc. The second and the third part require close-ended responses based on the 4- point Likert scale for agreement (the range was strongly agree-agree-disagree- strongly disagree) while the fourth part requires open-ended responses to allow translation instructors to give more details. In addition, the second part included 7 statements about instructors 'perceptions regarding the general evaluation methods which they usually apply in teaching translation courses before Coronavirus pandemic while the third part contained 11 statements about evaluation methods in translation courses during Coronavirus pandemic. The fourth part included 10 questions about instructors' suggestions regarding the appropriate evaluation models to be followed under the current online distance learning. To ensure validity, some items were subsequently added and some modified 
according to the comments obtained by two university instructors. The survey link was distributed via email to translation instructors who work at Saudi universities then the answers were statistically analysed by Google forms. To elicit accurate and objective responses from the participants, the following points were taken into consideration: 1) both the significance and the purpose of the study were explained to them, and 2) the participants answered the questionnaire items anonymously, so they felt at ease in answering the questions objectively.

\section{Results and Discussion}

The current study aimed at investigating the perspectives of instructors who teach translation courses at some Saudi universities towards the followed evaluation methods in teaching during Coronavirus pandemic. Consequently, the researcher attempted to provide university instructors with some suggested evaluation methods to cope with online teaching during Coronavirus crisis.

First of all, it is important to mention that the task of evaluating students' translations is not an easy task for university instructors. For example, in this study $90.5 \%$ of instructors strongly agree with this statement: "correcting translation assignments requires a lot of personal efforts compared with other courses" while $9.5 \%$ agree with the same statement as it was shown in figure 1 below:

\section{The task of correcting translation assignments may need a lot of personal efforts to provide students with convinced feedback compared with other courses. 21 responses}

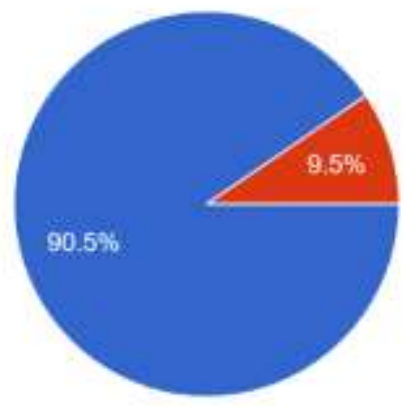

Strongly agree

agree

Disagree

strongly disagree

Figure1. Instructors' perceptions regarding correcting translation assignments

The figure above emphasized what Bahameed (2019) mentioned in his research regarding the student evaluation issue in translation. He mentioned that evaluating the performance of students seems confusing for instructors in translation courses due to the variety of translation mistakes made by students in translation tasks and he added that it is not possible to deal with all these mistakes by using one translation method or approach. Through this questionnaire, the 21 participants were provided with 18 statements and were asked 10 questions which are related to translation evaluation methods under three main headings:

1. General evaluation methods which they usually apply in teaching translation courses before Coronavirus pandemic.

2. Evaluation methods used in evaluating students in translation courses online during Coronavirus pandemic.

3. Suggested evaluation methods used in evaluating students in translation courses to cope with Coronavirus pandemic.

The most important results of this questionnaire will be discussed below based on the statements that were provided.

4.1 Problems of evaluation methods in translation courses during Coronavirus pandemic with some suggested solutions During Coronavirus pandemic, translation instructors encountered a number of problems in evaluating their students in translation tasks. One of these problems is that online exams and assignments were less fair to show the individual differences among students compared with written exams before Coronavirus pandemic. Figure 2 below illustrates the 
agreement of 71.4 of instructors with this statement (33.3\% of instructors strongly agree while $38.1 \%$ of instructors agree with the same statement)

4. Online exams are less fair to show the individual differences among students compared with written exams in class.

21 responses

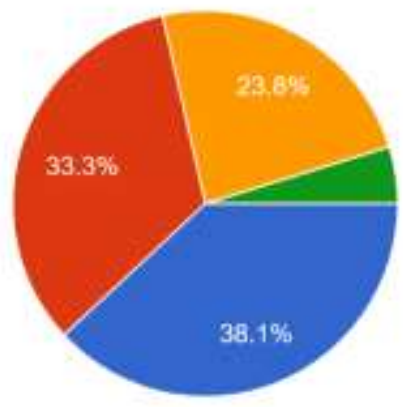

Strongly Agree

Agree

Disagree

Strongly Disagree

Figure 2. Instructors' responses towards unfairness of online exams

5. Online assignments are less fair to show the individual differences among students compared with written exams in class.

21 responses

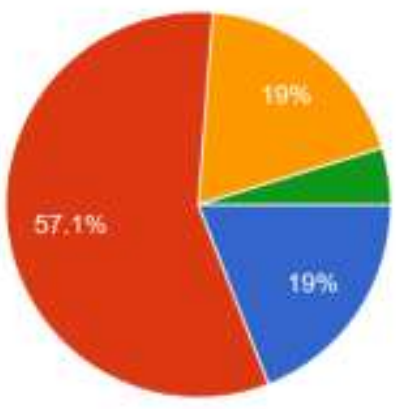

Strongly agree

Agree

Disagree

Strongly disagree

Figure 3. Instructors' perceptions towards unfairness of Online assignments

In comparison, 20 participants expressed more agreement with fairness of written exams as an assessment task before Coronavirus pandemic (over $95 \%$ of responses agree with this statement ( $47.6 \%$ strongly agree/ $47.6 \%$ agree) as illustrated in figure 4 . below: 


\section{Printed exams at class are fair to guarantee fairness among students.}

21 responses

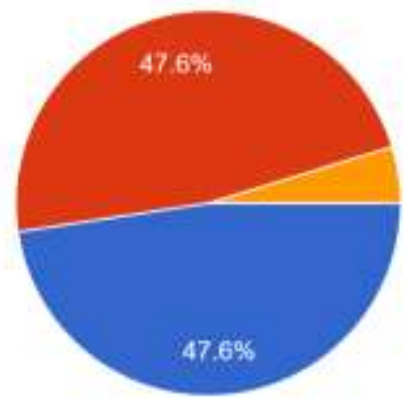

Strongly agree

Agree

Disagree

Strongly disagree

Figure 4. Fairness of printed/written exams in translation courses before Coronavirus pandemic

As a result of this comparison, it may not be suitable to use the same evaluation methods that instructors were used to apply before Coronavirus pandemic to cope with online teaching under this pandemic. For example, major written exams can be modified to suit the current situation. Through this study, over $90 \%$ of responses agreed on modifying the questions 'patterns of some translation exams and assignments as a suggested solution to this problem:

10. The questions' patterns of some translation exams and assignments should be changed to cope with online teaching.

21 responses

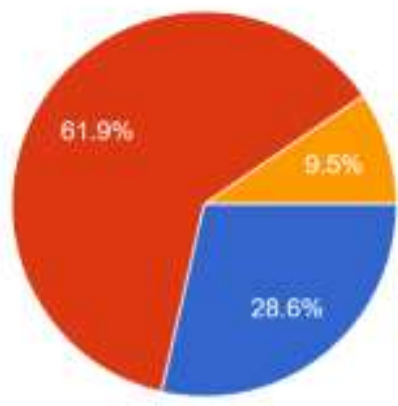

Strongly agree

Agree

Disagree

Strongly disagree

Figure5. Instructors' agreement with modifying questions' patterns of written exams

It is worth mentioning that over $23.8 \%$ of participants strongly agreed on modifying written exams into other alternative evaluation methods which can be added to enrich course specifications and $57.1 \%$ of participants strongly agreed on the same statement as illustrated in Figure6. below. 


\section{Some written exams in course specifications can be changed into other alternative evaluation} methods like extra assignments.

21 responses

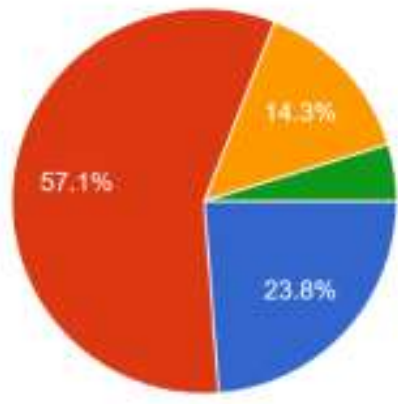

strongly agree

agree

disagree

strongly disagree

Figure 6. Instructors' agreement on modifying written exams during Coronavirus pandemic

Another comparison between the importance of class activities and participation before Coronavirus pandemic and that of live session and online participation under the pandemic should be taken into consideration in order to suggest a suitable evaluation method in translation courses. As shown in figure 7 above, more than $66 \%$ of the participants (14 out of 21 participants) strongly agree with the importance of class participation and activities as assessment tasks to reflect individual differences among translation students before Coronavirus pandemic and 28.6 $\%$ agree on the same statement.

\section{As a university instructor, you depend on participation and class activities in translation courses} to reflect the individual differences among your students.

21 responses

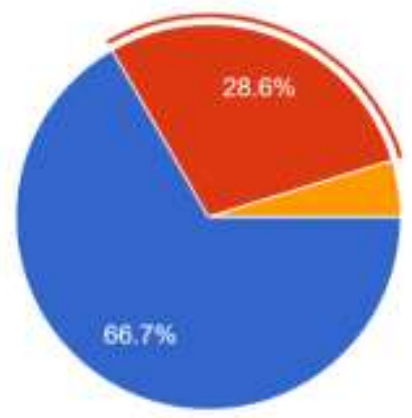

Strongly agree

Agree

Disagree

Strongly disagree

Figure 7. Instructors' perceptions on Class participation and activities reflect individual differences before Coronavirus pandemic

In comparison with assessment tasks during Coronavirus pandemic, 33.3\% of participants strongly agree on the importance of taking seriously into consideration student attendance of live sessions and their participation when translation instructors evaluate students. Moreover, $57.1 \%$ agree with the statement as shown in figure8 below. 


\section{Student attendance of live sessions and their participation should be seriously taken into consideration when you evaluate your students \\ 21 responses}

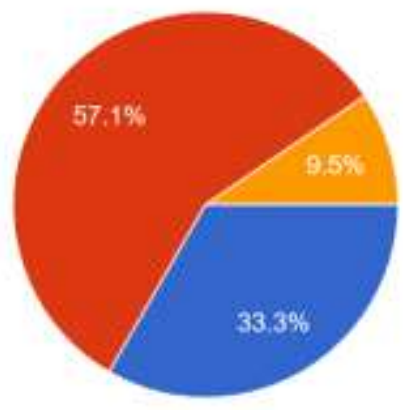

Strongly Agree

Agree

Disagree

Strongly Disagree

Figure 8. Importance of live sessions and online participation as assessment tasks for students during Coronavirus Pandemic

Another main problem in evaluating students' performance was using machine translation and CAT tools by students in doing assessment tasks during Coronavirus pandemic could lead to unfairness among students. $81 \%$ of participants strongly agree with this statement and $9.5 \%$ agree on that as shown in figure 9 below:

\section{Regardless of the nature of your translation course, using machine translation and some CAT tools by your students in performing online exams does not guarantee fairness among them. 21 responses}

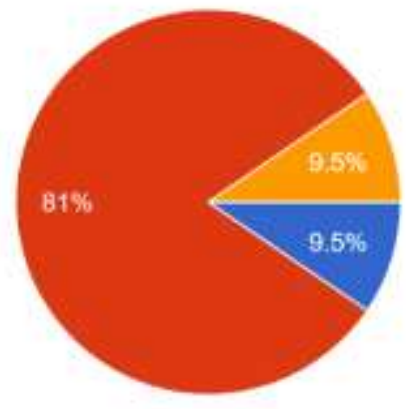

strongly agree

agree

disagree

strongly disagree

Figure 9. Using machine translation and CAT tools and unfairness of evaluation

Furthermore, the 21 participants were asked within the last part of the online questionnaire whether the online teaching affects the quality of learning positively or negatively. Their answers were classified according to the previous question into four sections as it was shown in table 4 below: 9 participants believe that online teaching affects the quality of learning negatively during Coronavirus pandemic whereas only 4 participants think that it affects the quality of learning positively. On the other hand, only one participant said that the online teaching affects the quality of learning positively and negatively while 7 participants mentioned almost neutral answers regarding the same question. As a result, the highest percentage was for those who believe that online teaching affects negatively the quality of learning. 
Table (4) Participants' answers regards the effect of online teaching on the quality of learning in translation courses

\begin{tabular}{|c|c|c|c|c|}
\hline No & Positively & Negatively & Both & Other Answers \\
\hline 1 & $\begin{array}{l}\text { Positively as the students' } \\
\text { participation increases gradually }\end{array}$ & $\begin{array}{l}\text { Yes, negatively affected; some learners scored } \\
\text { high grade in online assignments and exams. } \\
\text { However, before online learning they hardly } \\
\text { passed in some courses. }\end{array}$ & Both & N/A \\
\hline 2 & $\begin{array}{l}\text { No, it did not have any negative } \\
\text { effect. Using apps provided life- } \\
\text { like training }\end{array}$ & $\begin{array}{l}\text { Negatively, because the human presence in } \\
\text { teaching is of utmost importance. }\end{array}$ & & $\mathrm{N} / \mathrm{A}$ \\
\hline 3 & $\begin{array}{l}\text { Regular mode of teaching may } \\
\text { be said to be better in here in } \\
\text { the sense that the teacher can } \\
\text { keep a more meaningful eye on } \\
\text { the students' performance }\end{array}$ & $\begin{array}{l}\text { Negatively. I don't think online teaching is } \\
\text { sufficient nor sustainable in any major. }\end{array}$ & & / \\
\hline 4 & $\begin{array}{l}\text { It gave more room for creativity } \\
\text { whereby students feel more } \\
\text { comfortable. As for translation } \\
\text { courses, it offered a chance to } \\
\text { use CAT tools especially in } \\
\text { classes where these CAT are not } \\
\text { accessible which I believe is an } \\
\text { advantage }\end{array}$ & $\begin{array}{l}\text { Negatively, because translation needs a f2f } \\
\text { learning }\end{array}$ & & $\begin{array}{l}\text { No } \\
\text { ( Neither } \\
\text { positively nor } \\
\text { negatively) }\end{array}$ \\
\hline 5 & . & $\begin{array}{l}\text { Mainly because the students are not interacting } \\
\text { with technology as they should be. for example, } \\
\text { they would be driving their cars while attending } \\
\text { the class losing their attention to the road } \\
\text { rather than the course. }\end{array}$ & & $\begin{array}{l}\text { No change } \\
\text { ( Neither } \\
\text { positively nor } \\
\text { negatively) }\end{array}$ \\
\hline 6 & & Negatively as students do not take it seriously & & $\begin{array}{l}\text { None } \\
\text { ( Neither } \\
\text { positively nor } \\
\text { negatively) }\end{array}$ \\
\hline 7 & & $\begin{array}{l}\text { Negatively because the direct interaction } \\
\text { between students and instructors was lost. }\end{array}$ & & $\begin{array}{l}\text { I did not teach } \\
\text { translation } \\
\text { during } \\
\text { Coronavirus } \\
\text { pandemic } \\
\end{array}$ \\
\hline 8 & & $\begin{array}{l}\text { Negatively, but because this is the first time we } \\
\text { apply such teaching methods. with time and } \\
\text { experiences the online teaching would be } \\
\text { improved and serve the education better }\end{array}$ & & \\
\hline 9 & & $\begin{array}{l}\text { The vast majority of students tend to give their } \\
\text { role as learners to another instructor to fill their } \\
\text { shoes, casting doubts on the credibility of the } \\
\text { performance level. }\end{array}$ & & \\
\hline
\end{tabular}

Through the open -ended questions (part D of the questionnaire), the participants mentioned a number of problems faced them in evaluating students during coronavirus pandemic and they refer in particular to the existence of the last problem and their answers were as the following:

- Using machine translation without any personal input (copy, paste)

- Verification of students' works.

- Relying on external resources hugely by students to do their homework and exams, thereby making it difficult to judge on their actual individual differences

- Mostly using machine translation such as google and bin thus credibility is not guaranteed. 
In addition to this, the researcher observed other problems which translation instructors may encounter during the current pandemic, for instance some written exams may not cope with online teaching and the similarities of answers among students in doing online assessment tasks. Therefore, the 21 participants asked to suggest some solutions to solve these problems and the previous ones. To solve the problem of similarities of answers among students in doing assessment tasks, some suggested solutions were mentioned by the participants in table 5 below:

Table (5) Some suggested solutions to the similarities of students' answers

\begin{tabular}{|l|l|}
\hline \hline 7. How do you evaluate similarities of students' answers in your translation tests online? \\
\hline \hline No. & Answer \\
\hline 1 & The two answers are not accepted. \\
\hline 2 & Plagiarism equals zero. \\
\hline 3 & $\begin{array}{l}\text { Before the pandemic I tested them online for extra marks, but I discovered that } 99 \% \text { of translations were } \\
\text { identical. So, I eliminated them all. They all claimed they did not cheat. }\end{array}$ \\
\hline 4 & Warning students is a way to tackle such an issue. \\
\hline 5 & $\begin{array}{l}\text { Only when they use the same CAT tools that the similarity shines. I discourage them from using MT and } \\
\text { they usually listen except for a few renegades. }\end{array}$ \\
\hline
\end{tabular}

Other problems mentioned in open-ended questions like lack of group/one-on-one discussions, the seriousness of students and some technical issues.

\subsection{Criteria for Translation Evaluation}

It may be quite difficult to unify suitable criteria to evaluate students' translations for all translation courses because the nature of these courses are different in English and translation programs at universities. However, the researcher attempted to set some general rules which instructors can rely on when they are preparing their own criteria especially under Coronavirus pandemic to evaluate their students based on the agreement of the majority of the participants in this study. The first rule is a student' translation should be evaluated on the base of comparative ST-TT analysis. This rule is derived from the base of House's model of assessment quality (Munday,2012). Through this study, it was noticed that $66.7 \%$ of participants agreed on using a comparative ST-TT analysis and $14.3 \%$ of participants strongly agreed on the same statement as it was shown in figure 10 below:

\section{University instructors should evaluate students' translations on the base of comparative ST-TT analysis in class. \\ 21 responses}

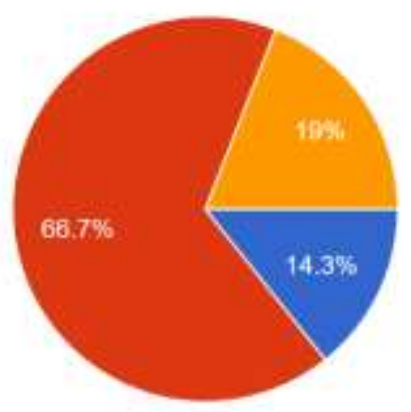

Strongly agree

Agree

Disagree

Strongly disagree

Figure 10. Instructors' agreement on using comparative ST-TT analysis in evaluating students' performance

Generally speaking, instructors can base their criteria on a theoretical model of quality assessment and that was agreed by $52.4 \%$ of participants in this study and $33.3 \%$ strongly agreed on the same statement as it was shown in figure 11 below. This means that more than $80 \%$ of participants agreed on the importance of this point. However, through open -ended questions, some participants suggested models such as domestication of texts -Venuti 2007, Nida -1964, Nida and Taber -1969, Catford- 
1965, House's model while some mentioned they depend on a college rubric system which is based on the American Translators Association model.

\section{University instructors must base their translation criteria for students on a theoretical model of translation quality assessment. \\ 21 responses}

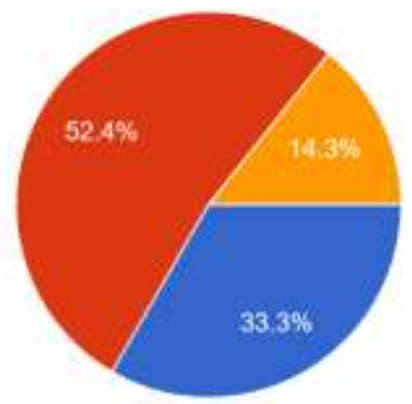

Strongly agree

Agree

Disagree

Strongly disagree

Figure11. Instructors' agreement with using a theoretical model in evaluating students' performance

Another important result is that $57.1 \%$ of participants agreed on focusing mainly on structural and lexical aspects of texts when they evaluate their students' translations online and 9.5\% strongly agreed on that as it was shown in figure 12 below. This leads us to the second rule in evaluation criteria, that is focusing on structural and lexical aspects of texts, sure other aspects of texts cannot be neglected especially paralinguistic aspects of texts.

\section{You mainly focus on structural and lexical aspects of texts when you evaluate your students} 'translations online.

21 responses

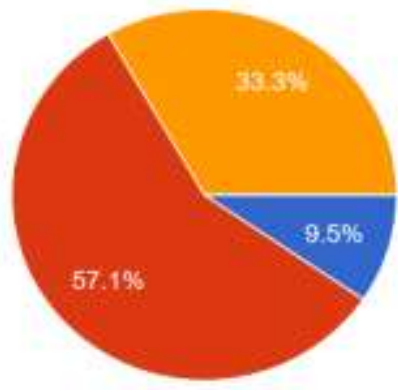

Strongly Agree

Agree

Disagree

Strongly Disagree

Figure 12. Participants' agreement on structural and lexical aspects of texts in translation evaluation

Through the open-ended questions, it was obvious that unifying evaluation criteria seems difficult among translation instructors even before Coronavirus pandemic as it was shown in table 8 below. However, the various criteria given by some participants in table (6) below can lead us to the third rule when translation instructors prepare their own evaluation criteria for students. 
Table (6) criteria in evaluating students' translation by some participants before Coronavirus pandemic

\begin{tabular}{|l|l|}
\hline No. & $\begin{array}{l}\text { 1. What are the major criteria you followed to evaluate your students' translations in general before Coronavirus } \\
\text { pandemic? }\end{array}$ \\
\hline 1 & Online homework feedback, In-class practice, quizzes, tests \\
\hline 2 & Learning outcomes \\
\hline 3 & using the right theoretical frame work to address the purpose of the TT. \\
\hline 4 & Meaning and structure \\
\hline 5 & Written translation tasks for translation courses and oral for interpretation \\
\hline 6 & written exams plus terminology quiz \\
\hline 7 & Meaning, clarity, application of translation theories, grammar and punctuation \\
\hline 8 & Meaning, structure, spelling and precision \\
\hline 9 & In-class activities, pre-class assignments, group work and collective discussions of translations. \\
\hline 10 & Correct meaning transfer + correct language formulation in TT \\
\hline 11 & $\begin{array}{l}\text { Being a teacher of literary Translation, accuracy, communicativeness, informativeness and literariness are the main } \\
\text { criteria I usually keep in view while evaluating students' translation work. }\end{array}$ \\
\hline 12 & $\begin{array}{l}\text { Assessing competences reflected in their translations including: linguistic/cultural (L1/L2), knowledge, and transfer } \\
\text { competences. }\end{array}$ \\
\hline 13 & clarity \\
\hline
\end{tabular}

As a result, the third rule is related to what Nida (Monday, 2012) called the requirements of successful translation: "(1) making sense; (2) conveying the spirit and manner of the original; (3) having a natural and easy form of expression; (4) producing a similar response." p.67. Thus, these requirements should be involved in translation criteria.

It is worth mentioning, over $75 \%$ of participants agree on the necessity of providing them with additional instructions regarding some suitable evaluation methods to cope with the current crisis as it was shown in figure 13.

\section{You need additional instructions regarding other suitable evaluation methods to achieve course objectives in light of the Coronavirus crisis. \\ 21 responses}

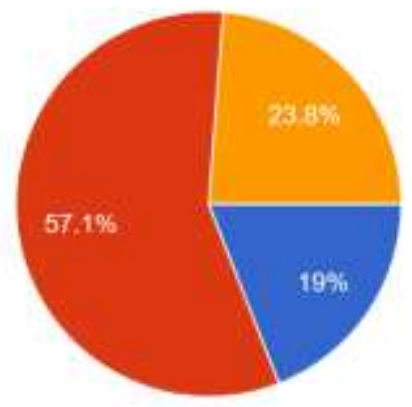

Strongly Agree

Agree

Disagree

Strongly Disagree

Figure 13. Importance of providing translation instructors with suitable evaluation methods during Coronavirus pandemic

This indicates that there are challenges in evaluating students during this crisis so that some challenges with some solutions were discussed in the last sections and more suggestions will be mentioned in the next section.

\subsection{Suggested evaluation methods for translation courses:}

Through the last part of the online questionnaire, the researcher asked the 21 participants about some suggested evaluation methods they prefer to use to cope with the online teaching of translation courses during Coronavirus pandemic. Some participants suggested some solutions in the open-ended questions of this questionnaire as shown in table 10 below. Moreover, the participants mentioned some software programs that can be useful in order to facilitate the task of evaluation in front of instructors although some participants are still depend on traditional way of evaluating. 
Table (7) Summary of most important suggested evaluation methods and main software programs

\begin{tabular}{|c|c|}
\hline $\begin{array}{l}\text { Some suggested evaluation methods that participants prefer to use to } \\
\text { cope with the online teaching }\end{array}$ & $\begin{array}{l}\text { Some main software programs and internet resources } \\
\text { used by participants in evaluating students' } \\
\text { performance }\end{array}$ \\
\hline Oral live sessions and class participation & Blackboard tools \\
\hline Online quizzes & Zoom and WhatsApp \\
\hline In-class tasks; home-assignments followed by discussions & BLEU \\
\hline $\begin{array}{l}\text { The texts should be segmented into smaller question and phrases with } \\
\text { specific issue in mind rather than providing whole texts to be translated } \\
\text { in addition to apply time constrains. }\end{array}$ & Trados \\
\hline Choosing the correct TT from 3 or 4 choices. & Scanning tests via anti plagiarism detectors \\
\hline Oral translation would do better and interviews. & Grammarly can help to some extent. \\
\hline \multicolumn{2}{|l|}{ Recent issues for assignments, presentations, projects, discussion, etc. } \\
\hline \multicolumn{2}{|l|}{ Students' presentations } \\
\hline \multicolumn{2}{|l|}{ written assignments, multiple choice editing questions, editing texts } \\
\hline \multicolumn{2}{|l|}{ Commentary } \\
\hline \multicolumn{2}{|l|}{ Live oral assessment } \\
\hline $\begin{array}{l}\text { I think we should take a major step and incorporate MT in our courses. } \\
\text { The students are then evaluated on their post-editing skills. It's only a } \\
\text { matter of time anyway that we would have no choice but to do that. }\end{array}$ & \\
\hline
\end{tabular}

\section{Conclusion}

The present study attempted to investigate the perspectives of instructors who teach translation courses at some Saudi universities towards the followed evaluation methods in teaching during Coronavirus pandemic. The 21 university instructors encountered some problems in evaluating students' performance since this task generally requires more efforts compared with other courses. The most important problems are the similarity of answers among students, students 'usage of machine translations and CAT tools in doing assessment tasks during Coronavirus pandemic. Among the suggested evaluation methods are modifying written exams into alternative online tasks for example, oral live assessment, editing texts, multiple choice editing texts, etc. In addition, enriching course specifications of new suggested evaluation methods and criteria. Further research is needed to examine the effectiveness of oral live assessment, multiple choice editing texts, etc. in teaching translation courses from students' perspectives. Also, further work is required to highlight the effectiveness of some suggested evaluation methods in this study in teaching certain translation courses at other universities.

\section{References}

[1] Al-Melhi, A. (2014). Pedagogical implications of utilizing translation evaluation strategies with translation students: Toward a model of teaching translation. Arab World English Journal, special issue on translation 3,11-26.

[2] Al-Qinai, J. (2000). Translation quality assessment. strategies, parameters and procedures. Meta, 45(3), $497-519$. https://doi.org/10.7202/001878ar

[3] Bahameed, A. S. (2019). Saudi MA translators: An evaluation issue. Arab World English Journal (AWEJ), special issue: the dynamics of EFL in Saudi Arabia, 22- 31. DOI: https://dx.doi.org/10.24093/awej/efl1.2

[4] Conde, T. (2013). Translation versus language errors in translation evaluation. In D. Tisagari, \& R. Van Deemter (Eds), Assessment issues in language translation and interpreting (pp.15-33). Peter Lang GmbH.

[5] Demuyakor, J. (2020). Coronavirus (COVID-19) and online learning in higher institutions of education: A survey of the perceptions of Ghanaian international students in China. Online Journal of Communication and Media Technologies, 10(3), e202018. https://doi.org/10.29333/ojcmt/8286

[6] Dewis, H. (2015, December). Comparing two translation assessment models: correlating student revisions and perspectives. (Doctoral dissertation,Kent State university).Ohio link. http://rave.ohiolink.edu/etdc/view?acc_num=kent1448504394

[7] Kiraly, D.C. (1995). Pathways to translation: pedagogy and process translation studies (1st ed.). Kent State University Press.

[8] Mobaraki.M., \& Aminzadeh.S. (2012). A study on different translation evaluation strategies to introduce an eclectic method. International Journal of English Linguistics, 2(6),36-70. doi:10.5539/ijel.v2n6p63

[9] Munday, J. (2012). Introducing translation studies: theories and applications ( $3^{\text {rd }}$ ed.). London and New Routledge.

[10] Wu, F. (2013). How do we assess students in the interpreting examinations?. In D. Tisagari, \& R. Van Deemter (Eds), Assessment issues in language translation and interpreting (pp.15-33). Peter Lang GmbH. 